RASĀYAN J. Chem.

Vol. 13 | No. 4 |2413-2419| October - December | 2020 ISSN: 0974-1496 | e-ISSN: 0976-0083 | CODEN: RJCABP

\title{
ADSORPTION OF AMMONIA AND METHYLENE BLUE USING COMBINATION OF COST-EFFECTIVE COCONUT HUSK ACTIVATED CARBON AND SILICA $\left(\mathrm{SiO}_{2}\right)$ AS AN ADSORBENT
}

\author{
Mariana $^{1,2, *}$, F. Mulana ${ }^{1}$, D. N. Pratama ${ }^{3}$ and S. Muchtar ${ }^{1}$ \\ ${ }^{1}$ Department of Chemical Engineering, Syiah Kuala University, 23111, Banda Aceh, Indonesia \\ ${ }^{2}$ Research Center for Environmental and Natural Resources, Universitas Syiah Kuala, Banda \\ Aceh 23111, Indonesia \\ ${ }^{3}$ Graduate School of Chemical Engineering, Syiah Kuala University, 23111, Banda Aceh, \\ Indonesia \\ *E-mail: mariana_hasyim@yahoo.com
}

\begin{abstract}
Ammonia and methylene blue are hazardous industrial wastes which are dangerous to health and the environment. Adsorption is one of several separation processes that can be employed to reduce these contaminants in water. Activated carbon is the most commonly used adsorbent for this process due to its high adsorption effectivity. However, adsorbents with one type of activated carbon generally have lower adsorption efficiency hence modification such as treatment and combination was proposed. This study aims to explore the potential of the combination of silica and coconut husk activated carbon for the removal of ammonia and methylene blue in industrial liquid waste. Several types of adsorbent were used in this research namely pure silica (activated and nonactivated), coconut husk (activated and nonactivated) and the combined pure silica-coconut husk (with combination ratio of 70:30). The results showed that the coconut husk-pure silica combined adsorbent showed the best adsorption performance in terms of removal efficiency and adsorption capacity for both methylene blue and ammonia. The removal efficiency of ammonia and methylene blue was $99.49 \%$ and $83 \%$, respectively. Whereas, the adsorption capacities of this combined adsorbent were $0.017 \mathrm{mg} / \mathrm{g}$ and $1.3913 \mathrm{mg} / \mathrm{g}$ for methylene blue and ammonia, respectively.
\end{abstract}

Keywords: Silica, Coconut Husk, Activated Carbon, Adsorbent, Ammonia, Methylene Blue.

(C) RASĀYAN. All rights reserved

\section{INTRODUCTION}

Over the past decades, the contamination of water by industrial-source wastes has become a global problem and requires serious attention. ${ }^{1,2}$ Most industries produce hazardous wastes and are often disposed of directly into water bodies. Such wastes are synthetic dyes from the textile (e.g. batik-manufacturing) industry like methylene blue. ${ }^{3}$ The presence of methylene blue in the water bodies at high doses is risky for human health as well as aquatic habitats. Also, the contamination of water bodies decreases environmental aesthetic values. ${ }^{3,4}$ Besides dyes, there is also chemicals contaminant such as ammonia generated from the liquid waste of tofu-making industry. ${ }^{5}$ The high ammonia content in tofu liquid-waste is from the breakdown of protein and fat in soybeans by microorganisms. Ammonia is the toxic end-product of the metabolism reaction of nitrogen. Thus, liquid waste containing high concentrations of ammonia, especially free ammonia is very toxic to aquatic biota. ${ }^{5}$ It was reported that ammonia content in water bodies with a concentration of over $1 \mathrm{mg} / \mathrm{l}$ is lethal to fish. ${ }^{5,6} \mathrm{It}$ is specified by Indonesian national regulation that the permitted disposal level of methylene blue to the environment is not more than $0.5 \mathrm{mg} / \mathrm{L} .{ }^{7}$ For that reason, treatment is needed to lower or even remove the content of these contaminants.

Many methods have been reported to solve this problem such as extraction, membrane separation, ion exchange and adsorption. The adsorption method is the most widely used and preferred. ${ }^{8}$ Adsorption is a process that occurs when a fluid (liquid or gas) is caught by a solid and formed as a thin film on the surface of the solid material or commonly named adsorbent. ${ }^{9}$ As it is cost-effective, easy and safe of operation and Rasayan J. Chem., 13(4), 2413-2419(2020)

http://dx.doi.org/10.31788/ RJC.2020.1346006 
RASĀYAN $J$. Chem.

Vol. 13 | No. 4 |2413-2419| October - December | 2020

does not hurt the environment, adsorption has been popularly preferred and applied in many removal processes. ${ }^{9-12}$ Conventionally, activated carbon and zeolite are the most frequently used adsorbents, however, the adsorption capacity of these two adsorbents is quite low in removing dyes due to their microporous characteristic. ${ }^{13}$

Recently, it has been reported that silica is an adsorbent material showing a fairly high adsorption performance against heavy metals, dyes, phenolic compounds, pesticides and so forth in the water. This is because silica is a nontoxic mesoporous material having large pore volume and surface area as well as outstanding stability. ${ }^{13}$ However, it should be noted that with increasing consumption for applications in the industrial field, the economical value of commercial silica also increases. Hence, the production of silica from more affordable sources is highly considered. One of the most promising sources comes from agricultural biomass wastes. All of these natural materials have the potential to be used as adsorbents due to high lignocellulose content. ${ }^{14}$ These waste biomaterials are suitable to be selected as an alternative source for adsorbent materials because, in addition to having renewable sources, inexpensive and available in large quantities, the preparation of adsorbents from these materials also helps in reducing production costs because the processing generally only involves washing, drying, and size reducement. ${ }^{13}$

Amongst many potential biomass-waste sources that were used widely as adsorbents, we chose coconut husk $(\mathrm{CH})$ to be studied. Besides content high lignin, hemicellulose, and cellulose, ${ }^{14}$ silica-containing ash can be produced from $\mathrm{CH}$ through thermal treatment with the controlled condition, the produced amorphous silica is highly promising to be used as an adsorbent. ${ }^{15}$

A few numbers of literature reported the utilization of $\mathrm{CH}$ as an adsorbent for the removal of wastewater contaminants. Hasany et al studied the performance of $\mathrm{CH}$ adsorbent in the removal of Cd (II), $\mathrm{Cr}$ (III) and $\mathrm{Hg}$ (II) metals. ${ }^{16}$ Jain et al used CH adsorbent for removal of tropaeoline dye and it was disclosed that the activated $\mathrm{CH}$ sorbent showcased performance that is as good as that of commercial activated carbon. ${ }^{17}$ However, pure adsorbent tends to have low adsorption capacity, hence various treatments and modifications are developed to enhance their performance. The modification can be done chemically like alkaline treatment, acid treatment, the bleaching treatment and by combining the adsorbent with another material. ${ }^{18}$ Manju et a ${ }^{19}$ impregnated $\mathrm{CH}$ adsorbent with copper and successfully improved the adsorption capacity to arsenic. Modification can also be carried out physically as conducted by Foo et al in which they activated $\mathrm{CH}$-based adsorbent by microwave irradiation. ${ }^{20}$

In this study, we investigated the performance of the $\mathrm{CH}$-sourced and pure commercial silica adsorbents. The study aims to compare whether the performance of low-cost based natural adsorbents can match that of commercial silica. Also, these two types of silica-based adsorbents are combined to obtain an adsorbent with better performance. The preparation of the adsorbents was reported in our previous work ${ }^{7}$, therefore, in this paper, the continuation of research is reported only in terms of performance evaluation of prepared $\mathrm{CH}$ and silica adsorbents for removal of ammonia from tofu-making liquid waste and methylene blue as representative waste from batik-manufacturing industry.

\section{EXPERIMENTAL}

\section{Materials}

Coconut husk collected from the area of Neuheun, Aceh Besar was used as biomass-source to produce adsorbent. The pure commercial silica was purchased from Merck and also used as an adsorbent. $\mathrm{H}_{2} \mathrm{SO}_{4}$ with the purity of $98 \%$ (Merck) with a concentration of $0.1 \mathrm{M}$, ammonia, methylene blue and distilled water were also involved during the preparation, activation and performance test of adsorbents.

\section{Preparation and Activation of Adsorbent}

The preparation of adsorbent from $\mathrm{CH}$ was carried out as reported in our earlier work. ${ }^{7}$ The raw $\mathrm{CH}$ with a total weight of $10 \mathrm{~kg}$ was heated to form carbon in a muffle furnace. The obtained $\mathrm{CH}$ carbon and pure silica were mixed while stirring for 2 hours. The sorbent mixture was dried overnight in the oven to remove the water content. After that, the sorbent was soaked in $\mathrm{H}_{2} \mathrm{SO}_{4}$ solution in a $500 \mathrm{ml}$ flask for 24 hours then drained and filtered. It was then followed by $\mathrm{pH}$ neutralization using rinsing using water. Subsequently, the sorbent was calcined for 2 hours at a temperature of $800^{\circ} \mathrm{C} .{ }^{21}$ Finally, silica as much as 10 grams was dispersed in distilled water with a silica-to-water ratio of 10:1, followed by drying and carbonation. At last, the activated sorbent was sieved to 100 mesh size. 
RASĀYAN $J$. Chem.

Vol. 13 | No. 4 |2413-2419| October - December | 2020

\section{Adsorbent Adsorption of Ammonia and Methylene Blue}

The adsorption experiment was conducted as follows. $100 \mathrm{ml}$ of methylene blue dan $100 \mathrm{ml}$ of ammonia was separately put into the $200 \mathrm{ml}$ flasks. The adsorbent was added into each flask with a dosage of 0.2 gram for methylene blue-containing flasks and 0.5 gram for ammonia-containing flasks. The mixture was stirred for 2 hours then filtered and followed by an analysis of ammonia and methylene blue concentrations by using UV-Visible Spectrophotometer (Pharmaspec-1700, Shimadzu).

\section{Efficiency and Capacity of Methylene Blue Adsorption}

\section{RESULTS AND DISCUSSION}

Several parameters such as the sorbent dosage, the concentration and $\mathrm{pH}$ of feed solution greatly influence the efficiency or removal process by adsorption..$^{22}$ In this experiment, the initial concentration of methylene blue is $0.04 \mathrm{ppm}$ and five types of adsorbents are used i.e. non-activated coconut husk $(\mathrm{NCH})$, activated coconut husk $(\mathrm{ACH})$, non-activated pure silica $(\mathrm{NSi})$, activated pure silica $(\mathrm{ASi})$, and activated combined coconut husk-pure silica (CHSi). From the results of the experiment, it is revealed that the efficiency of methylene blue removal is highly affected by the difference in adsorbent types, activation process, and contact time, as shown in Fig.-1.

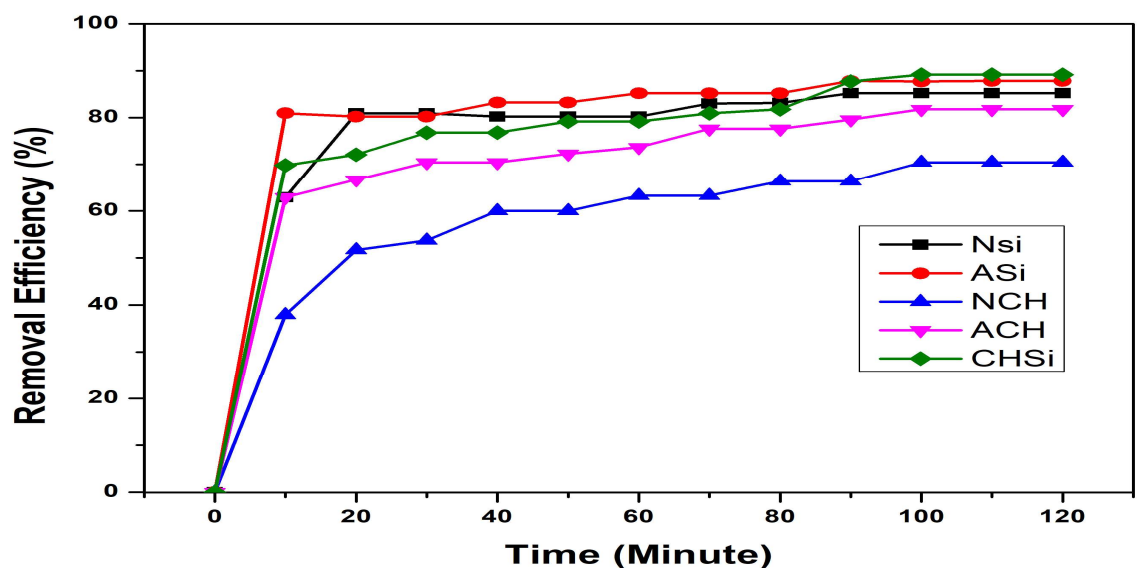

Fig.-1: The Removal Efficiency (\%) of Methylene Blue

Figure-1 shows that the removal efficiency slightly differs for each adsorbent with the CHSi adsorbent resulting in the highest value of $89.16 \%$ at 120 minutes of adsorption time and the lowest efficiency was obtained at adsorption using non-activated $\mathrm{CH}(\mathrm{NCH})$ adsorbent $(70.41 \%)$. Meanwhile, the adsorption capacity using $\mathrm{ACH}$ and $\mathrm{Si}$ adsorbents achieved removal efficiency of $81.77 \%$, and $85.20 \%$, respectively. The dismissal of methylene blue from the solution occurs due to the reaction between methylene blue and silica in the prepared adsorbents, the reaction is as follows:

$$
\mathrm{SiO}-+\mathrm{MB}+----\rightarrow \mathrm{Si}-\mathrm{O}-\mathrm{MB}^{+}
$$

The negatively charged oxygen atom in the silica oxide compound binds the positively charged $\mathrm{N}$ atom in the methylene blue compound which facilitates the adsorption of methylene blue by the active $\mathrm{SiO}_{2}{ }^{23}$ The CHSi adsorbent gives the highest efficiency in removing methylene blue due to the presence of more silica content with the addition of pure silica as confirmed by the XRD analysis, where the CHSi adsorbent has $83 \%$ silica, meanwhile the silica content in $\mathrm{NCH}, \mathrm{ACH}$ and $\mathrm{NSi}$ adsorbents is 62,75 , and $63.2 \%$, respectively. The capacity of adsorption indicates the quantity of adsorbent that can be adsorbed by the adsorbent. ${ }^{22}$ Figure- 2 showed the effect of several types of adsorbents on the capacity of methylene blue adsorption.

The results in Fig.-2 revealed that the adsorption capacity improved with prolonged adsorption duration. The highest value was achieved at 120 minutes of adsorption time for all types of the adsorbent. The respective adsorption capacity for $\mathrm{CHSi}, \mathrm{ACH}, \mathrm{NCH}$, and $\mathrm{ASi}$ adsorbents were $0.0178 \mathrm{mg} / \mathrm{g}, 0.0163 \mathrm{mg} / \mathrm{g}$, $0.0140 \mathrm{mg} / \mathrm{g}$, and $0.0175 \mathrm{mg} / \mathrm{g}$. Similar to results of removal efficiency, the high adsorption capacity of 
RASĀYAN $J$. Chem.

Vol. 13 | No. 4 |2413-2419| October - December | 2020

combined coconut husk and pure silica (CHSi) adsorbent is due to the higher composition of $\mathrm{SiO}_{2}$ in comparison to the other adsorbent types. ${ }^{7,24}$ Also, the chemical activation also plays part in enhancing the adsorption performance of the adsorbents, as seen from the results, the activated adsorbents (ACH) has better adsorption capacity and efficiency than the non-activated adsorbent $(\mathrm{NCH})$.

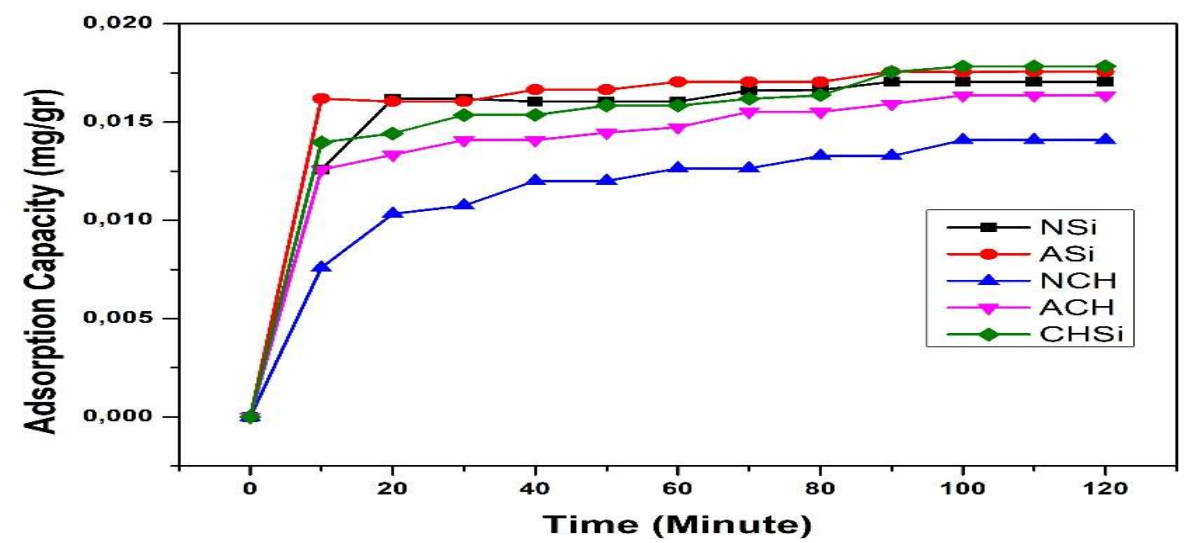

Fig.-2: The Adsorption Capacity (mg/g) of Methylene Blue

\section{Efficiency and Capacity of Ammonia Adsorption}

For this experiment, $6 \mathrm{ppm}$ artificial ammonia was used for the adsorption process using 2 types of adsorbents namely CHSi and ACH adsorbents with a dosage of 0.5 gram. It is revealed that the types of adsorbents, the contact time and activation treatment on the adsorbents affect the removal efficiency of ammonia. The results are presented in Fig.-3.

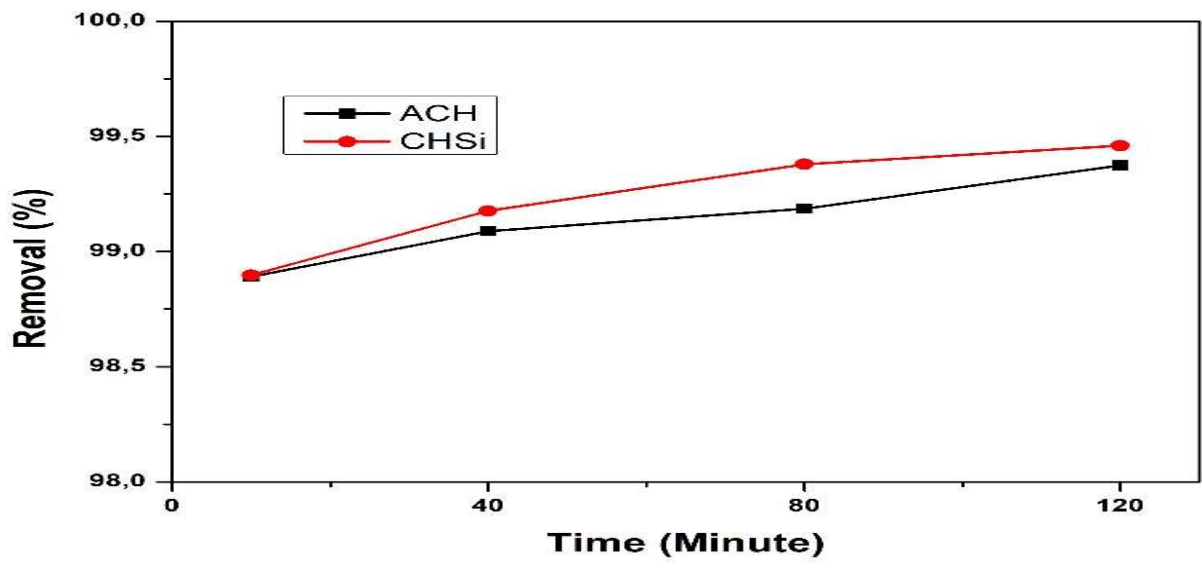

Fig.-3: The Removal Efficiency (\%) of Ammonia

Figure-3 shows that the combined CHSi adsorbent achieved the highest removal efficiency of $99.45 \%$ after the adsorption process for 120 minutes. This is due to the higher silica content in the coconut husk adsorbent combined with pure silica (CHSi) rather than in the coconut husk adsorbent only $(\mathrm{ACH})$. According to $\mathrm{XRD}$ analysis reported elsewhere, the $\mathrm{CHSi}$ adsorbent prepared with $\mathrm{CH}$-to-silica combination ratio of $70: 30$ contains $83 \%$ silica. $^{7}$

Figure-4 shows that at an adsorption time of 120 minutes, the CHSi adsorbed $1.3924 \mathrm{mg} / \mathrm{g}$ of ammonia, meanwhile the $\mathrm{ACH}$ adsorbed lower ammonia as much as $1.391 \mathrm{mg} / \mathrm{g}$. It can be concluded that the combined adsorbent has a slightly better adsorption capacity compared to coconut husk adsorbent only. This is due to the higher content of $\mathrm{SiO}_{2}$ and higher surface area as well as pore volume of CHSi compared to the ACH adsorbent. ${ }^{7}$

As reported in our earlier work, ${ }^{7}$ the composition of $\mathrm{SiO}_{2}$ in the 70:30 CHSi is higher than that of ASi and $\mathrm{ACH}$. The high content of $\mathrm{SiO}_{2}$ is advantageous for an adsorbent as it promotes the reactivity of sorbent 
RASĀYAN $J$. Chem.

Vol. 13 | No. 4 |2413-2419| October - December | 2020

which means 70:30 CHSi has better reactivity compared to the other two adsorbents (ASi and ACH) ${ }^{24}$ It is reported that with a higher level of silica, makes the adsorbent to have better adsorption and ion exchange performance. $^{25}$

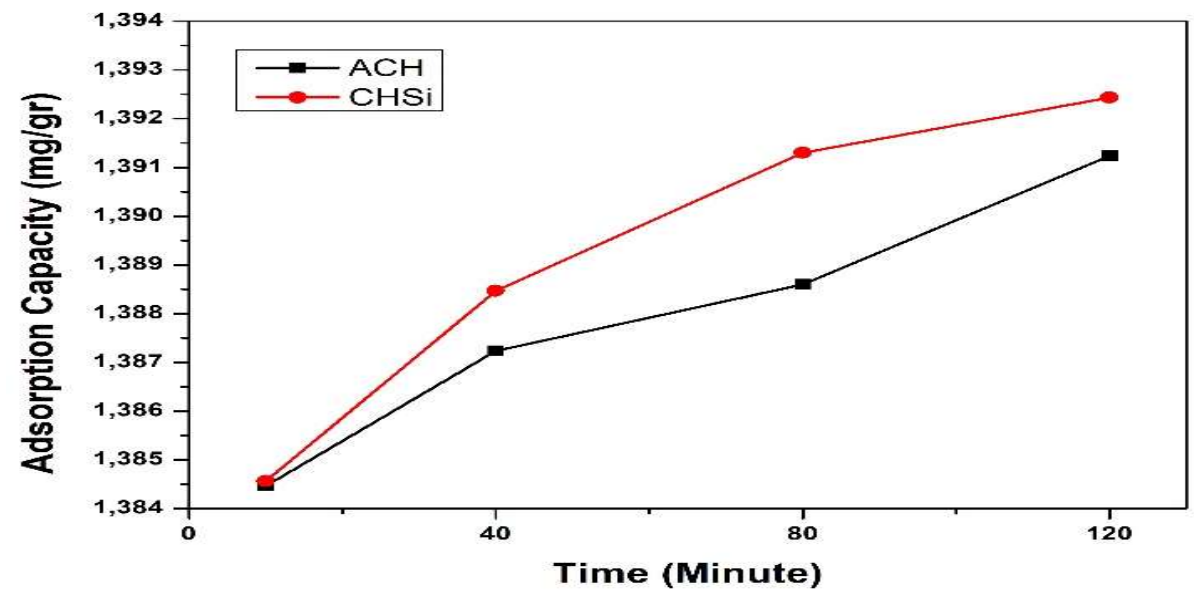

Fig.-4: The Adsorption Capacity (mg/g) of Coconut Husk-based Adsorbents

The Effects of Adsorbent Variables on the Adsorption Performance

For this study, only CHSi adsorbent is used as it showcases the best performance amongst the other prepared adsorbents in previous experiments. Meanwhile, the adsorption time and mass of the adsorbent are varied. For the adsorption experiment on ammonia, the adsorbent used is 0.5 gram, whereas 0.2 gram of adsorbent is used for adsorption in the removal test of methylene blue. The influences of these variables on the removal efficiency of both ammonia and methylene blue are presented in Fig.-5.

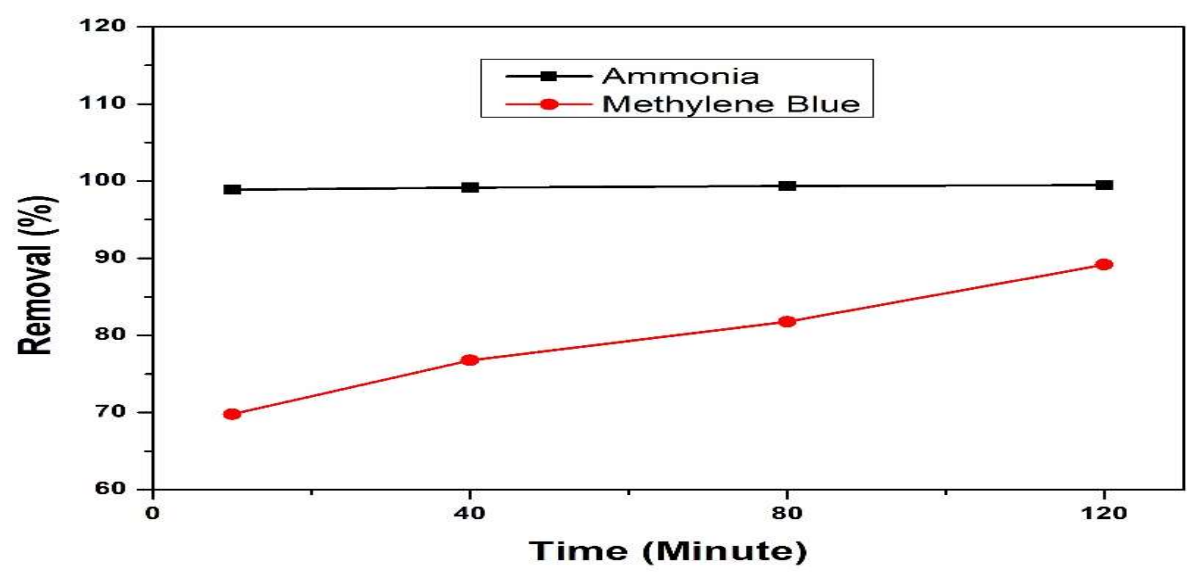

Fig.-5: The Removal Efficiency of Ammonia and Methylene Blue

The results in Fig.-5 confirm that using a higher amount of adsorbent leads to higher removal efficiency. As observed from Fig.-5, the ammonia removal efficiency is higher than that of methylene at the same adsorption time and adsorbent type. For the methylene blue sample, the adsorption was conducted by using 0.2 gram CHSi adsorbents, whereas, for ammonia, the removal process was carried out with the addition of 0.5 gram CHSi as adsorbent. This is because, with the increasing amount of the adsorbent, more particles and surface area are available to reactively adsorb the adsorbate in the sample. ${ }^{7}$ Moreover, the lower removal efficiency of methylene blue adsorption is because dyes such as methylene blue are very complex compounds so that methylene blue is more difficult to decompose or eliminate compared to an organic component like ammonia. ${ }^{27}$

\section{CONCLUSION}

A low-cost natural material of coconut husk has been prepared with various activation treatment and combination with pure commercial silica. Also, the adsorption performances on the ammonia and 
RASĀYAN $J$. Chem.

Vol. 13 | No. 4 |2413-2419| October - December | 2020

methylene blue removal were evaluated in this report. The activated coconut husk adsorbent showed an excellent performance in removing ammonia and methylene blue in liquid waste. The combining the coconut husk adsorbent with pure silica further improved the removal efficiency and adsorption capacity for both ammonia and methylene blue samples due to increasing content of silica and pore volume as well as surface area properties. The best adsorption performance was achieved when using the adsorbent amount of 0.5 gram and the adsorption process contact time of 120 minutes.

\section{REFERENCES}

1. S. K. Dubey, R. Yadav, R. K. Chaturvedi, R. K. Yadav, V. K. Sharma, and P. S. Minhas, Bulletin of Environmental Contamination and Toxicology, 85, 295(2010), DOI:10.1007/s00128-010-0073-2.

2. P. C. Mishra, P. C. Behera, and R. K. Patel, Journal of Environmental Science \& Engineering, 47, 141 (2005).

3. R. Kant, Natural Science, 4, 22 (2012), DOI:10.4236/ns.2012.41004

4. M. T. Yagub, T. K. Sen, S. Afroze, and H. M. Ang, Advances in Colloid and Interface Science, 209, 172 (2014), DOI:10.1016/j.cis.2014.04.002

5. S. Prabowo, and R. Tindangen, IOP Conference Series: Earth and Environmental Science, 012046 (2018), DOI:10.1088/1755-1315/144/1/012046

6. R. R. Karri, J. N. Sahu, and V. Chimmiri, Journal of Molecular Liquids, 261, 21(2018), DOI: 10.1016/j.molliq.2018.03.120

7. M. Mariana, F. Mulana, S. Sofyana, N. Dian, and M. Lubis, IOP Conference Series: Materials Science and Engineering, 012022 (2019), DOI: 10.1088/1757-899X/523/1/012022

8. M. Mariana, F. Mulana, and L. Juniar, Rasayan Journal of Chemistry, 13, 139(2020), DOI:1 $0.31788 /$ RJC.2020.1315377

9. P. Loganathan, S. Vigneswaran, J. Kandasamy, and R. Naidu, Journal of Hazardous Materials, 248249, 1(2013), DOI:10.1016/j.jhazmat.2012.12.043

10. F. Yu, C. Yang, Z. Zhu, X. Bai, and J. Ma, Science of The Total Environment, 694, 133643(2019), DOI: $10.1016 /$ j.scitotenv.2019.133643

11. D. M. RUTHVEN, 2007, Adsorption Kinetics: Theory, Applications And Recent Progress, In L. Zhpu, Adsorption: Progress in Fundamental and Application Research, World Scientific, China, pp. 3-28. DOI: 10.1142/9789812770264_0001

12. J. A. S. Costa, R. A. de Jesus, D. O. Santos, J. F. Mano, L. P. C. Romão, and C. M. Paranhos, Microporous and Mesoporous Materials, 291, 109698 (2020), DOI: 10.1016/j.micromeso.2019.109698

13. N. Yuan, H. Cai, T. Liu, Q. Huang, and X. Zhang, Adsorption Science \& Technology, 37, 333(2019), DOI: $10.1177 / 0263617419827438$

14. A. K. Samanta, G. Basu, and L. Mishra, Industrial Crops and Products, 117, 20(2018), DOI: 10.1016/j.indcrop.2018.02.080

15. R. Bayuaji, R. Kurniawan, A. Yasin, H. A. Fatoni, and F. Lutfi, IOP Conference Series: Materials Science and Engineering, 012014 (2016), DOI:10.1088/1757-899X/128/1/012014

16. S. M. Hasany, and R. Ahmad, Journal of Environmental Management, 81, 286(2006), DOI: 10.1016/j.jenvman.2006.01.009

17. R. Jain, and M. Shrivastava, Journal of Hazardous Materials, 158, 549(2008), DOI: 10.1016/j.jhazmat.2008.01.101

18. K. Johari, N. Saman, S. T. Song, C. S. Chin, H. Kong, and H. Mat, International Biodeterioration \& Biodegradation, 109, 45(2016), DOI:10.1016/j.ibiod.2016.01.004

19. G. N. Manju, C. Raji, and T. S. Anirudhan, Water Research, 32, 3062(1998), DOI:10.1016/S00431354(98)00068-2

20. K. Y. Foo, and B. H. Hameed, Chemical Engineering Journal, 184, 57(2012), DOI: 10.1016/j.cej.2011.12.084

21. M. Mariana, Y. Oobuchi, A. Maezawa, and S. Uchida, Journal of the Chinese Institute of Chemical Engineers, 35, 491(2004). 
RASĀYAN J. Chem.

Vol. 13 | No. 4 |2413-2419| October - December | 2020

22. K. A. Tan, N. Morad, T. T. Teng, I. Norli, P. Panneerselvam, APCBEE Procedia, 1, 83(2012), DOI: 10.1016/j.apcbee.2012.03.015

23. A. S. ALzaydien, American Journal of Applied Sciences, 6, 1047(2009), DOI: 10.3844/ajessp.2009.197.208

24. J. N. Naat, T. Lapailaka, A. Sabarudin, and R. T. Tjahjanto, Rasayan Journal of Chemistry, 11, 1467 (2018), DOI:10.31788/RJC.2018.1144055

25. M. L. Firdaus, F. E. Madina, F. Sasti Yulia, R. Elvia, N. Soraya, D. R. Ishmah, and A. P. Cid-Andres, Rasayan Journal of Chemistry, 13, 249 (2020), DOI:10.31788/RJC.2020.1315496

26. A. H. Jawad, R. A. Rashid, M. A. M. Ishak, and L. D. J. D. Wilson, Desanlination and Water Treatment, 57, 25194 (2016), DOI:10.1080/19443994.2016.1144534

27. A. K. Kushwaha, N. Gupta, and M. C. Chattopadhyaya, Desalination and Water Treatment, 52, 4527 (2014), DOI:10.1080/19443994.2013.803319

[RJC-6006/2020] 